\title{
La conferencia de Dalí en el Parque Güell en 1956
}

\author{
Joan Bassegoda i Nonell \\ Cátedra Gaudí, Barcelona
}

En ocasión de las Fiestas de la Merced de 1956, el Secretario de "Amigos de Gaudi", Enrique Casanelles Farré (1914-1968) y el Vice-presidente de la entidad, José María Garrut Romà, decidieron proponer a Dalí que diera una conferencia en el Park Güell sobre Gaudí, visto el extraordinario éxito de una anterior conferencia de Gaudí en el Ateneo Barcelonés. Garrut visitó a Dalí en su casa de Port Lligat y le sugirió la idea de la conferencia. Dalí acogió con entusiasmo la idea pero rogó a Garrut que lo llamara dentro de un tiempo pues tenía que pedir permiso a Gala. Concedido el permiso se organizó la conferencia a la que asistieron cerca de cinco mil personas al Park Güell para las cuales hubo que alquilar sillas plegables de madera. Gala se sentó en uno de los sillones Clapés de la Casa Museo en un saledizo del muro que cierra el Teatro Griego, Dalí permaneció a su lado siendo presentado por Federico Gallo.

La cárcel para Radio Nacional y filmado por el noticiario NO-DO. Dalí propuso que a su alrededor durante la conferencia se movieran sueltos un buen número de pollos y de cabras, pero no fue posible como tampoco su idea de que aviones a reacción en vuelo rasante pararan por encima del recinto. La idea de la conferencia y el temor a sus excentricidades hizo que ni el presidente de "Amigos de Gaudi", don Eusebio Güell Jover, vizconde de Güell (1904-1990), ni los arquitectos de la Sagrada Familia Isidro Puig Boada y Luis Bonet Garí estuvieran presentes en el acto.

Terminada la lectura de la conferencia Dalí pintó con alquitrán encima de una Iona el perfil de la Sagrada Familia y, acto seguido, se sometió al interrogatorio del público. Terminado el acto se dobló la lona y quedó en el parque. Al día siguiente no pudieron desdoblarla porque el alquitrán había unido las partes y la obra de Dalí se perdió irremisiblemente.

Anexo documental: Texto de la Conferencia de Dalí en el Park Güell, 29 de septiembre de 1956

"Xiquets de Valls, vosotros sois como una Egipto (sic), pero una Egipto al revés, porqué Egipto elevó pirámides de piedras muertas a la muerte y vosotros eleváis torres de carne y hueso vivos al cielo de la mística española.

* BASSEGODA I NONELL, Joan: “La conferencia de Dalí en el Parque Güell en 1956", Boletín de Arte n 28 Departamento de Historia del Arte, Universidad de Málaga, 2007, págs. 607-610. 
Un español, el pintor Mariano Fortuny, es un genio; yo también. Gaudí es un genio; yo también. Prim, Fortuny, Gaudí son de Reus; yo también. Yo también poque, como escribió nuestro filósofo Francisco Pujols, en nuestro país hay muchas gentes que si no son de Reus, casi lo parecen. Yo también, porque, como escribió nuestro filósofo Eugenio Montes, en momentos actuales de terrible depresión moral y espiritual, es un honor vivir y ser español; los de Figueres, los de Port Lligat, lo mismo que los de Sevilla, El Escorial, España toda entera, sabiendo la importancia de nuestro país, formamos esa tierra unida, esa tierra mística, esa tierra del siglo y de la unidad espiritual.

En una ocasión fue preguntado Gaudí dónde estaban los planos de su catedral de la Sagrada Familia, y respondió que hacía arquitectura sin planos, pero los tenía en la mente. En 1927, el mismo día en que llegué a París, desayuné con el místico y protestante Le Corbousier (sic) y viendo mi creación diosiniana, inquirió si tenía idea de lo que la arquitectura del futuro podía llegar a ser y yo le respondí que Dalí tenía idea de todo y sobre todo. La arquitectura del porvenir, respondí, será blanda y peluda. Blanda ya lo está siendo con Gaudí y peluda lo será por Dalí, y también entonces elevaré miradas al poder creador de Gaudí. Y así mismo lo ha reconocido últimamente el propio Le Courbusier en las últimas fases de la arquitectura ya que en ellas impera la gravedad sobre las formas helicoidales de acuerdo con nuestro genio Gaudí.

Ahora me voy a Nueva York, desde Port Lligat, y allí continuaré lo que hoy he empezado aquí y daré solución a la obra más grande y genial que los arquitectos hayan nunca soñado, o sea la proporción de que las nuevas leyes tienen que ser un producto del coeficiente de elasticidad de la sección áurea y de la divina proporción del Renacimiento del Tretinia (sic) y del fraile Lucas Paciollo (sic). Dado que estos últimos 20 años he estado en contacto con lo que se puede llamare la flor de los intelectuales, los filósofos de la arquitectura y constatando que hay algunos que más o menos se imponen rozando la genialidad, digo que cuando un español sale genial, no se puede comparar con nadie; únicamente somos sordos en nuestro propio país; pero de Velázquez no ha habido en España más que uno y de Gaudí no ha habido más que Gaudí y tardarán muchos siglos antes no se produzca otro igual, lo mismo que estoy convencido que nuestro Generalísimo Franco es el mejor gobernante y Jefe de Estado que Europa ha tenido y producido después de la guerra.

Hace algún tiempo cayó una bomba en Hiroshima y después han venido las bombas de hidrógeno, pero los pintores locales continúan pintando sus naturalezas muertas y sus árboles trazados más o menos oloquinos (sic) como si nada verdadero hubiera pasado, pero antes que la primera bomba, cayó en el propio corazón de Barcelona una bomba más temible y potente, porque en vez de ser una bomba destructiva fue una bomba creadora, en vez de ser una bomba uniforme, fue una bomba morfológica y, en vez de destruir, aniquilar 
desintegrar, en el lugar donde cayó, en este mismo corazón de Barcelona, se levantaron los edificios sublimes del arquitecto Gaudí; la prueba de lo que digo es que aquí, en nuestro país, no nos damos cuenta de la importancia cósmica de Gaudí, es el hecho que los Amigos de Gaudí tienen abierta en el Tinell una exposición maravillosa de documentos y objetos de Gaudi, y tenemos que hacer constar que ha sido casi exclusivamente visitada por extranjeros.

Como que las conferencias, menos las que yo pronuncio, suelen ser un acto de aburrimiento casi integral, considero mucho más eficaz pasar a la acción. Y realizar el cuadro que ya está aquí preparado. En la Escuela Real de San Fernando de Madrid gané el primer premio de pintura, pero hice una apuesta con los otros alumnos diciendo que ganaría el premio, sin que mi pincel rozara, ni tuviera el mínimo contacto con la tela. Realicé el cuadro echando 'tacas' (sic) de pintura a un metro de distancia, pero con una tal destreza, digna del pintor reusense Fortuny, que el resultado fue un desnudo femenino que me servía de modelo, el cual ganó, ya que los profesores desconocían mi método, el primer premio de la Escuela de Pintura, Escultura y Grabado. Pero no solamente gané el premio, sino que como en Madrid la gente estaba muy lejos de lo que pasaba en Europa, para ellos descubrí el divisionismo, el fontillismo (sic), y hubo una serie de pintores que especularon como si el fontillismo (sic) fuese una invención daliniana.

Esto que voy a hacer es mucho más importante, porque cuando me han dicho de venir a hacer la conferencia, he pensado que venir nada más que para hablar no valía la pena, y que era mucho más práctico que si me molestaba en venir desde Port Lligat a Barcelona para esta ocasión, me fuera habiendo acabado ya la Sagrada Familia; lo que vamos a hacer ahora, porque hago una profecía y doy mi palabra de honor de español que sería imposible terminar ideológicamente sin seguir las pautas del 'quitrán'.

Al pensar lo que haría ya lo he dicho esta mañana: Que si saliera bien, bien y si saliera mal, mejor; ha salido mucho mejor".

Coloquio final

1.- “¿Vd. se considera precursor de la era del 'quitrán’?

$\mathrm{Si}$.

2.- Me hacen la objeción de que este cuadro no lo he pintado yo.

Casi nunca los pintores pintan sus cuadros. Para empezar por los más geniales, como Rafael tenía por lo menos 15 discípulos que le hacían todo; lo importante no es la cosa manual, sino la idea.

3.- ¿Qué diferencia hay entre un artista pintor y un payaso pintor?

La sustancia; o sea que el payaso artista es superior a la clase de payaso, a pesar de que los payasos, en general, han tenido siempre una gran significación histórica y social. Los Reyes españoles de la época de Velázquez, estaban rodeados de payasos sublimes, a los cuales pedían incluso consejo y 
estaban dotados de un gran respeto. Si, además de un payaso genial, pinta maravillosamente bien, entonces ese señor que es payaso y pinta maravillosamente bien, es un genio.

4.- La marca y la fábrica del 'quitrán”

Ignoro las dos cosas.

5.- “¿Qué relación hay entre el "quitrán” y la mística angélica?”.

Muy clara y directa, porque lo que he hecho es un 'quitrán' caído y la mística angélica es el acto de levantar el ángel caído formando el ángel glorioso.

6.- Me pide qué opinión me merece el arte funcional actual.

$1^{\circ}$ que no funciona; $2^{\circ}$ es asquerosamente prosaico.

7.- ¿Qué relación tiene la sardana con el alquitrán?

Tiene una relación pitagórica, porque las dos son un producto pitagórico

de la ciencia de los números.

8.- ¿Tiene alguna relación el bigote de Dalí con el arte de Gaudí?

Una gran relación, porque mi bigote es absolutamente contrario a los bigotes nórdicos y depresivos que llevaba, por ejemplo Federico Nietsche, que llevaba unos bigotes depresivos que le caían hacia abajo, llenos de niebla y de música mal digerida.

En cambio, mis bigotes, son erectos y se dirigen hacia el cielo como las torres de los Xiquets de Valls o las torres de Gaudí.

9.-¿Se puede considerar terminada la Sagrada con este cuadro?

Está terminada la primera etapa o sea que aquí, como he dicho, ha salido muy mal, pues para que el plano de la serpiente hubiera dado las torres que yo había imaginado, hubiera tenido que ser completamente plano, pero la tela con su peso, ha creado una serie de irregularidades que ya preveíamos que saldrían., pero no tan mal como eso; Porque si hubiera salido tal como yo había previsto, ya no habría que hacer nada más, en cambio mañana empezaré partiendo de eso, pero la verdadera prueba de la Sagrada Familia tiene que ser hecha en volumen, porque no puede hacerse de una manera taquitaxista (sic), sino que tiene que ser en volumen. Únicamente un volumen de 'quitrán', que directamente sea derretido y varios volúmenes tardarán casi un mes en llegar al suelo y podrán someterse cada día a torsiones para lograr unas formas helicoidales que prueban la gloriosa obsesión de Gaudi”. 